Adegboye, O. \& Kotze, D. (2013). An exploratory look at associated factors of poverty on educational attainment in Africa and in-depth multilevel modelling for Namibia. Journal for Studies in Economics and Econometrics, 37(1): 105 http://hdl.handle.net/10520/EJC138182

\title{
An exploratory look at associated factors of poverty on Educational attainment in Africa and in-depth multi-level modelling for Namibia
}

\author{
O. Adegboye and Danelle Kotze
}

\begin{abstract}
This study examines several indicator variables related to education and poverty in Africa from the Demographic and Health Surveys (DHS). Many have described income and education as one of the fundamental determinants of health and as one of the indicators for socio-economic status. Firstly, data from thirty-six African countries were explored, geographical heterogeneity of the countries were discussed. Secondly, we carried out indepth multi-level analyses using generating estimating equations on data for 72,230 respondents and from 5,436 households in the Namibia DHS (1992-2006). Results from statistical analyses indicate that age of household head, socio-economic status of household, parent's level of education, family size and position of a child in the family play a significant role in the educational attainment of household members. We found that these household level characteristics are important predictors of educational attainment. Thus, government policy aimed at reducing household level poverty should be implemented to alleviate the economic power at household level thereby increasing educational attainment.
\end{abstract}

\section{Introduction}

Access to education particularly in the developing countries has been discouraging. The United Nations (UN) Universal Declaration of Human Rights Article 26 states that everyone has the right to education (United Nations, 1948). The Jomtien 1990 declaration of the "World Conference on Education For All" stipulates that every person (child, youth and adult) shall be able to benefit from educational opportunities designed to meet his/her basic needs. Education has also been described as a tool for economic development and eradication of poverty. Schooling improves productivity, health and reduces negative features of life such as child labour as well as bringing empowerment (EFA Global Monitoring Report, 2002). Education paves the way to empower people to obtain access to jobs and higher wages. This in turn allows individuals to acquire resources (economic power) to access basic health facilities and, thus, improve the health of the population. It was reported that a country with a higher percentage of its youth in schools considerably reduces its risk of conflict (Collier, 2007). Many have described the link between income and education as one of the fundamental determinants of health and one of the indicators for socio-economic status. 
A study based on cross sectional data from nine countries showed that an earnings inequality increases with educational inequality (Chiswick, 1971). In developing countries, the male child is favoured to go to school rather than the girls. The number of siblings may affect the continuation of school for some other family member as this poses an alternative cost. Bledsoe et al. (1999) found an association between schooling and fertility in less developed countries. The mother's educational attainment plays an important role in the household and has a significant effect on her bargaining power and thus her drive for education.

The United Nations Educational Scientific and Cultural Organization (UNESCO) reported that Sub-Sahara Africa had an increase in its average enrolment from 54 per cent to 70 per cent between 1999 and 2006. In Namibia, although the "primary education net enrolment keeps improving at levels of $92,3 \%$ in 2007 to $98,3 \%$ in 2009 , there is a worrying trend of not retaining the number of enrolled primary school learners in secondary education" (Ombudsman, 2010, p.2). The primary school completion rate in Namibia was about $80 \%$ in 2006 while the net enrolment rate in grades 1 to 7 had reached 92,3\% in 2007 (van der Berg and Moses, 2011 ). The Africa Recovery July 2000 report indicated that Tanzania has been more successful than many developing countries in achieving gender equality in education, with girls making up to 49,6 per cent of all enrolled primary school students in 1997. Further, the report noted that early marriage tends to cut short a girl's education at the upper primary and secondary levels in Tanzania. Other details from this report showed that $76 \%$ of children in Nigeria had access to primary school education; the southwest region recorded the highest percentage while the southeast recorded the lowest percentage. Accessibility to basic schooling and region dummy could explain the $99 \%$ variation in income inequality in Nigeria and suggested that income redistribution in favour of the northern region will reduce income inequality in Nigeria (Alabi, 2008). The war in southern Sudan was associated with educational inequality in that country according to Deng (2003). Aluede (2006) discussed the variations in educational development in Nigeria; he noted that this disparity could be traced to historical educational development in Nigeria. Alabi and Abu (2008), in Alabi (2008) particularly attributed the persistent crisis in the Niger-Delta to low educational attainment of the people in that region. In 2004 Namibia was the country with the greatest income inequality in the world with a Gini coefficient of 0,7 (Ombudsman, 2010; Levine and Roberts, 2008). The central bureau of statistics of Namibia in 1996 reported that about $38 \%$ of the people were poor and $9 \%$ were severely poor (Levine and Roberts, 2008).

For the past five decades there has been a clamour for an increase in educational enrolment and attainment in developing countries. The first two goals of the UN Millennium Development Goals target the increase in school enrolment to be observed by 2015, an eradication of extreme poverty and hunger by the same date, and that all children must have access to and be able to complete primary school by this time.

The current study is structured as follows: Firstly we descriptively examine the performance of African countries in achieving these goals in space and time and to gain a better understanding of factors that need improvement. These are the factors that 
influence educational enrolment and, thus, educational attainment using empirical evidence to explain the relationships. It is important to understand how poverty affects the educational attainment and enrolment and to explore the socio- economic realities of poor households. It becomes necessary to gain an idea of education distributions, wealth distributions and their inequalities. Moreover, it is of interest to document trends in educational attainment and poverty using data from Demographic Health Surveys. During this investigation, other household characteristics: parent education, socioeconomic status, family size, living conditions and location will be explored. Secondly the exploratory analyses of the wider group of African countries' educational attainment will be followed by a representative in-depth analysis of associated factors of poverty on educational attainment in Namibia using data from Namibia Demographic and Health Surveys (1992-2006).

\section{Data and variables}

\section{Data}

Demographic and Health Surveys (DHS) have been conducted in more than 85 countries worldwide since 1984, including in Africa. The DHS are based on national representative data and provide information on the population and health situation. The data are available for download on the website of ICF Macro International (www.measuredhs.com). The main interest is specifically to collect information at household and individual levels, and the information collected includes fertility, family planning, maternal and child health, educational characteristics, wealth index, ownership of basic facilities and location.

We restrict ourselves to data drawn from Phase II (1988-1993) to Phase V (2003- 2008), due to the fact that Phase I surveys are outdated and sometimes do not match with the current questionnaire used in other phases of the survey. Data are not available for all African countries; therefore, we only use data on countries where available and for different phases.

Similar variables were extracted from all surveys at household and individual level. Individuals in the same household shared the same characteristics such as age of parents, parent's education, number of rooms, wealth index, household head etc. Our dataset was aggregated at three levels: household, national and continent, and using common survey indicators across countries and DHS phases.

A total of 1,716,945 observations from 401,493 households and from a total of 36 African countries were collected from 1988 (DHS II) to 2008 (DHS V). Table 1 and Appendix 1 and 2 summarize the data characteristics. We considered only respondents between the ages of 5 years to 30 years, because in most African countries this is referred to as the school age (especially primary to tertiary). This data provide information on individual children and household characteristics.

\section{http://repository.uwc.ac.za}




\section{Variables definitions}

\section{Educational attainment}

Several definitions of educational attainment have been discussed in literature (Thomas et al., 2001: Gardner, 1998: Psacharopoulos and Arriagada, 1986: Barro and Lee, 2010). These centred on using different indicators, like years of schooling completed, level of education completed, ability to read (literacy) and so on.

Several problems are associated with obtaining the educational attainment indicator. In addition to problems associated with the definition of educational attainment, most African countries have different systems of education, as summarized in Appendix 3. The age of entrance to primary school varies across different countries, usually 6-7 years but can be as low as 4 years in Morocco. Moreover, the length of primary education also ranges from 6 years in many countries to 9 years in Mali, Morocco and Egypt. In Namibia, $84 \%$ of children ages 6-12 attend primary school (83\% of boys and $85 \%$ of girls) (Education Policy and Data Center, 2012).

The years of compulsory schooling differ in a number of the countries under study; it ranges from as low as 4 years in Senegal to 10 years in Comoros and Ethiopia. Egypt, Mali and Morocco have the lowest number of years of secondary education (3 years) with some countries having up to 7 years of secondary education (such as Benin, Burkina Faso, Cameroon, Central Africa, Chad, Comoros, Congo Brazzaville, Niger, Namibia, Senegal and Togo). In order to minimize problems associated with indicators not reported for some countries and the differences in education systems across African countries, we considered only the levels of education completed as an indicator for educational attainment. That is, the highest level of education completed by an individual is referred to as his/her educational attainment indicator variable and was divided into no education, primary, secondary education and above secondary education. These may be further subdivided as need arises for appropriate statistical analysis, such as proportion of the population with no education.

Table 1: Distribution of the survey data used in this study

\begin{tabular}{lcccc}
\hline Survey Phase & Observation & Male & Female & $\begin{array}{c}\text { Number of } \\
\text { Households }\end{array}$ \\
\hline DHS 2 & 261205 & 50,80 & 49,20 & 51788 \\
DHS 3 & 373865 & 50,99 & 49,01 & 81820 \\
DHS 4 & 596607 & 50,65 & 49,35 & 119237 \\
DHS 5 & 485268 & 50,72 & 49,28 & 129006 \\
\hline
\end{tabular}

\section{Education Gini}

The Education Gini was used as a measure of inequality in educational attainment while the standard deviation of schooling measures absolute dispersion. The methods of Thomas et al. (2001) using both direct formulae were adapted as follows: 
Gini: $E_{L}=\left(\frac{1}{\mu}\right) \sum_{i=2}^{i-1} \sum_{j=1}^{i-1} P_{i}\left|y_{i}-y_{j}\right| P_{j}$

Educational attainment (mean education levels): $\mu=\sum_{i=1}^{n} P_{i} y_{i}$

Standard deviation $\sigma=\sqrt{\sum_{i=1}^{n} P_{i}\left(y_{i}-\mu\right)^{2}}$

Where

EL is the education Gini based on educational attainment distribution, large populations

$\mu$ is the average educational attainment for the concerned population

$\mathrm{Pi}$ and $\mathrm{Pj}$ are the proportions of the population with certain levels of educational attainment

$\mathrm{yi}$ and yj are the different educational attainment levels and $\mathrm{n}$ is the number of levels/categories in attainment data.

The Gini value can be interpreted as follows: a Gini value of zero implies a perfect equality while a Gini value of one implies a perfect inequality. The severity of the inequality depends on how close the Gini coefficient is to 1.

\section{Poverty indicators}

Providing a single, generally accepted definition of poverty and its measurement is a very difficult task. Peter Townsend (1979) defined poverty as "the absence or inadequacy of those diets, amenities, standards, services and activities which are common or customary in society". Many authors have proposed ways of estimating poverty: Gibson (2000) suggested monetary or non-monetary measures when using poverty-focused household surveys, Ravallion (1994) suggested the "well-being" for poverty and further argued for welfarist and the non-welfarist approaches.

Measuring poverty indicators over time from household surveys have setbacks as data may not be collected from the same household over time presenting a repeated crosssectional survey. In order to make comparison analyses across countries, any poverty indicator must be available in all surveys. DHS does not provide information on household income or expenditures; however, a poverty profile can be constructed using information on household assets.

DHSs provide wealth quintiles as a measure of economic status based on all household assets and utility services, including country-specific items and sometimes ownership of agricultural land and domestic servants while excluding family size and age structure.

The wealth quintiles were calculated using principal component analysis (PCA); this procedure first standardizes the indicator variables (calculating z-scores), then, the factor coefficient scores (factor loadings) are calculated, and finally, for each household, the 
indicator values are multiplied by the loadings and summed to produce the household's index value. In this process, only the first of the factors produced is used to represent the wealth index. The resulting sum is itself a standardized score with a mean of zero and a standard deviation of one (Rutstein and Kiersten, 2004). The idea of PCA is to find an orthogonal transformation of the original variables (vector of assets correspondent to every household) to a new set of uncorrelated variables called principal components, which are ranked in decreasing order of importance (Chatfield and Collins, 1980).

For this study, the DHS wealth quintile was used. These poverty indicators (the wealth quintiles or wealth index score) were estimated relatively, that is, the proportion of the current status (for example, poorest 20 per cent of the population in each year). The advantage of using DHS wealth quintiles is that it allows a potential comparison across countries and over time, and can be linked to other indicators like education and health. In addition to the wealth index, family size and household structure (family structure) were included in the poverty indicator. Other explanatory variables considered are as follows: number of wives, age, sampling weight, gender, country, household characteristics, gender of household head, own child, type of residence, literacy gap, parent educational attainment, sanitation and access to clean water.

\section{Descriptive analyses}

Various data exploration techniques were applied: summary statistics were obtained in order to gain insight into the data. Plots for various covariates were used to investigate any trend or pattern in the indicator variables (See Appendix 2 for the list of variables). Significant association exists between poverty and health outcomes; wealthy people have limitless access to good health facilities and good education and will most likely be better educated and live longer. An investigation of the education distribution can explain aspects about the poverty level in a household, region and country at large. Furthermore, the wealth distribution and education distribution may also play an important role in health distribution.

Education has been described as one of the indicators for national socio-economic development and that the proportion of literate population is a good indicator of development (Gardner, 1998). As it is shown in Appendix 4, the proportion of literate population in Africa has risen over time (survey phase), while population with no education has decreased. Educational indicators will be used to make clear the distribution and inequality of educational attainment across countries.

The plots of educational attainment in Appendix 5 showed that in DHS II (1988- 1993), Burkina Faso, Morocco, Niger and Senegal had more people with no education than primary education. Over the years, many countries have seen an increase in primary enrolment and have seen a rise in the proportion of the population with at least primary education, but countries like Cote D'Ivoire, Liberia, Mali and Niger, however, still have more people with no education. Although, Namibia has seen an increase in the enrolment rates over the years, the proportion of the population with no education was not as low (6\%) as it was in DHS II (1992): 8\% in DHS IV (2000) and 9\% in DHS V (2006) ( not shown).

\section{http://repository.uwc.ac.za}




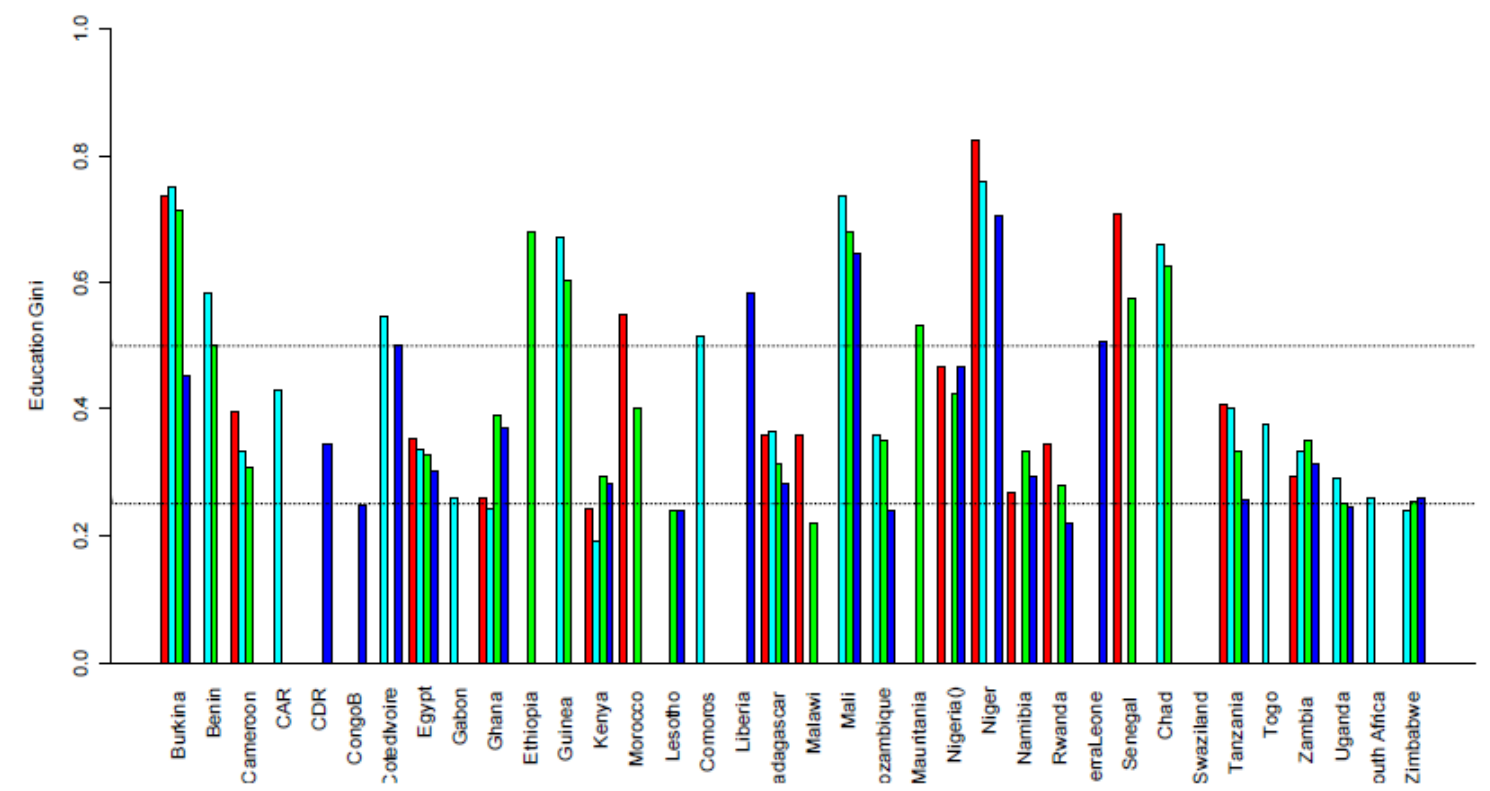

Figure 1: Education Gini for countries under study across different survey phases

Source: Authors calculation (See Appendix 1)

The Education Gini coefficient was calculated for each country to allow for country wide comparison and to assess countries with greater or lower educational inequality and to check the dynamics over time. Figure 1 gives a graphical display of the Gini coefficients across the 36 countries under study over different survey periods (DHS II to DHS V); this allows for comparison and assessment of education inequality among the countries (see Appendix 6). Most of the countries under study have been experiencing a steady decrease in educational inequality; some still record a high level of inequality. For example, Burkina Faso, Chad, Ethiopia, Guinea, Mali, Niger and Senegal have an Education Gini of at least 0,60 (Figure 1). The educational inequality in Namibia is one of the lowest in Africa with Gini coefficient of 0,26 in DHS II (1992), 0,33 in DHS IV (2000) and 0,29 in DHS V (2006) (Authors' calculation, Figure 1 and Appendix 6). This can be attributed to the changes in enrolment between 1992 and 2006. Looking at the Lorenz curve (not shown) Namibia, South Africa, Zimbabwe and Lesotho have the smallest area in DHS II, III, IV and V respectively. Niger has the highest inequality in DHS II, DHS III and DHS V with a Gini value of $0,83,0,76$ and 0,70 respectively, although the Gini value is decreasing.

Parent perception of education plays an important role in children's education; there exists a strong correlation between household head with no education and children with no education (Figure 2). Most countries clustered in the third quadrant of the graph are countries with less than $50 \%$ of the population with no education. In the extreme case, this is displayed in the first quadrant, indicating countries with over 50\% population with no education (household head and children); Burkina Faso, Mali and Niger (Figure 2). 


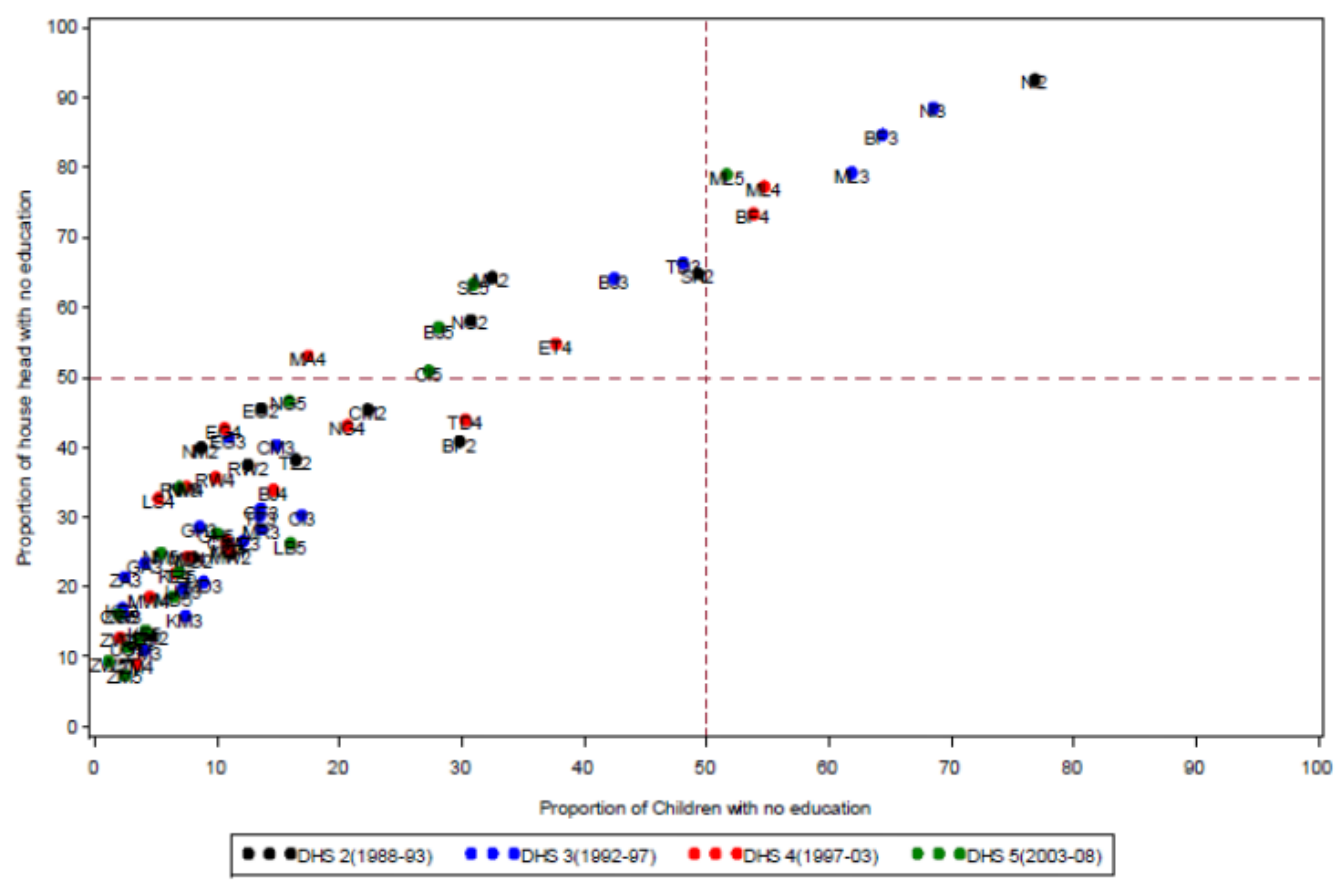

Figure 2: Relationship between proportion of household members (children) with no education and proportion of household heads with no education (country ID indicated on the dot for different survey phase)

Information about the distribution of the wealth index quintile by country over time is displayed in Appendix 7. The proportion of the poorest 40\% of the population increased from less than 30\% in DHS II in Burkina Faso to about 40\% in DHS V. This is lower than the proportion of the richest $20 \%$. The proportion of the poorest $40 \%$ generally has a share of above $25 \%$ of the population for the countries under study at all survey periods except Cote D'Ivore in DHS III, Mozambique and Nigeria in DHS V (Appendix 7). With high income inequality, the proportion of households in the poorest $40 \%$ in Namibia was about 42\% in 1992 (DHS II) but dropped to about 33\% in 2000 (DHS IV) and increased in 2006 (DHS V) to about 38\% (Authors' calculation: Appendix 6)

Gender differences in educational attainment (literacy gap) can be measured by the ratio of the proportion of male population with at least primary education to that of their female counterpart. Appendix 8 illustrates the result from these estimates; in DHSII, Niger recorded the highest difference in male to female ratio of educational attainment of about $25 \%$.

The proportion of males with at least primary education was about $35 \%$ more than females in Nigeria for DHS V. For most of the countries the percentage of males are more than that of females except Namibia (DHS II), South Africa (DHS III), Lesotho, Namibia and Rwanda (DHS IV) and Congo Brazzaville, Lesotho, Namibia and Rwanda (DHS V). These countries have seen significant changes in gender equality in educational attainment over time. Although there are fluctuations, it is safe to say that most of the countries under study are bridging the gap in the gender differences in educational attainment. These fluctuations may be attributed to changes in educational policies and systems over the years. 
Relationship between gender differences in the literacy gap and the educational attainment of a country cannot be overemphasized. There is a positive relationship between literacy gap and population with no education. Countries with higher literacy gap (above 20\%), like Niger, Burkina Faso, Mali and Benin, with the exception of Nigeria, have about $65 \%$ or higher percentage with no education. Similarly, these countries also have a lower proportion of the population with at least primary education. Namibia is one of the few countries in Africa that has achieved gender parity in education with fairly more females with at least primary education than males: $4 \%$ in 1992, 2,2 \% in 2000 and $2 \%$ in 2006.

The lack of access to and availability of clean, safe drinking water and clean sanitation is another major cause of poverty in Africa. It is difficult to go to school when time is spent on a daily basis finding and transporting water. Many countries still cannot provide these basic amenities to their people. Moreover, several diseases are attributed to unhygienic living conditions and dirty water which, in turn, lead to poor health and poor productivity; poverty is inevitable in this situation. However, the percentage of population without access to clean and safe water are decreasing over time in many of the countries under study. A country like Nigeria has experienced a drastic reduction in the percentage of population without access to clean and safe water from above 95\% in DHS II to below $20 \%$ in DHS V. Egypt has maintained a low percentage over time and has lowest percentage of people without access to clean water (below 10\%) in DHS V, while Kenya, Liberia, Madagascar, Mali, Sierra Leon, Niger and Uganda still have around 70\% of the population without access to clean water (Source: Authors' calculation). In 1992 about $50 \%$ of households in Namibia did not have access to clean and safe water, this reduced to less than $30 \%$ in 2006. The average number of household size also reduced from about 10 in 1992 to 7 household members in 2006.

\section{A case study of Namibia DHS II, DHS IV and DHS V.}

\section{Methodology.}

Marginal models are often a better choice when dealing with dependencies in the dataset, without the need for complex and unattainable assumptions, as found in some other methods and can be used to answer research questions directly at the intended marginal level. In this study, individuals are nested within households; data were collected for every eligible member of our study at household level. Ignoring the structure of the data may result in parameter estimates to be asymptotically biased. In recognizing the structure of the survey data we use multi- level modelling of the individuals nested within households. Multi-level analysis allows for information to be pulled together from multiple levels and enable interrelationships between the different levels to be explored and facilitated for overall interpretation. Household members shared some information collected at household level, thus we would expect dependencies or correlation among these responses (i.e. within subject dependency). These dependencies or correlations must be accounted for by methods appropriate to the data (Diggle et al., 1994). Statistical methods that take the dependencies in the data into account should be used. Several models have been proposed for the analysis of such data. Most of these are extensions of the well-known logistic regression, a particular case of generalized linear models with

\section{http://repository.uwc.ac.za}


logit or probit link functions (McCullagh \& Nelder, 1989). They are usually classified into marginal or random-effects models.

A simple model for discrete data may assume a Poisson log-linear relationship between rates and other explanatory variables. Different approaches are available for implementing a multi-level analysis for cluster models or correlated data, that is, methods that simultaneously model all the outcomes elicited from an individual. Let Yij denote a binary outcome corresponding to the $\mathrm{j}^{\text {th }}$ household $\left(\mathrm{j}=1\right.$ to $\mathrm{ni}$ ) of the $\mathrm{ith}^{\text {th individual. }}$ Let also $\mathrm{Xij}$ be a design matrix consisting of covariate $(1 \times \mathrm{p})$ vectors, with the first element being 1 for the intercept. The marginal model, also called the populationaveraged model (Zeger et al., 1988), estimates the model, thus:

$\operatorname{logit}\left(\mathrm{E}\left(\mathrm{Y}_{\mathrm{ij}} \mid \mathrm{X}_{\mathrm{ij}}\right)\right)=\operatorname{logit}\left(\mathrm{P}\left(\mathrm{Y}_{\mathrm{ij}}=1 \mid \mathrm{X}_{\mathrm{ij}}\right)\right)=\mathrm{X}_{\mathrm{ij}}{ }^{\prime} \beta$ and under the marginal model the Odds Ratio $=\exp (\beta)$.

The marginal model supposes that the relationship between the outcome $\mathbf{Y}$ and the covariate $\mathbf{X}$ is the same for all subjects. Moreover, dependencies between observations within the same household are handled by fitting the vector of parameters, $\beta$, using the Generalized Estimating Equations (GEE) (Liang \& Zeger, 1986), wherein the covariance matrix is structured by using a working correlation matrix $R(\alpha)$, fully specified by the vector of parameters $\alpha$. This working correlation matrix is assumed to be the same for all the subjects, reflecting an average dependence among the observations for all subjects. In the marginal model, several specific choices of the structure of the working correlation matrix $\mathrm{R}(\alpha)$ are possible (see Liang \& Zeger, 1986). An advantage of the marginal model, as demonstrated (1986), is that $\beta$ and their robust variance are consistent (the estimator converges towards the parameter being estimated as the sample size increases) even when the correlation structure is misspecified. However, choosing the working correlation structure closest to the true structure increases the statistical efficiency of the parameter estimator. Consequently, it is recommended to specify the working correlation as accurately as possible, based on the knowledge of the process (Albert, 1999).

\section{Results}

This section discusses statistical analysis of a preselected dataset, by looking at the effect of some indicators on educational attainment. In Section 2.2, we have explored some indicator variables and identified countries with little or no improvement in these variables. In order to provide an in depth analysis of these variables and assess their significant influence, the statistical analysis using Generalized Estimating Equations (Liang \& Zeger, 1986) will be carried out on a sample of the data; that is, we would require a country with at least three survey data sets as an example, hence, the choice of Namibia. Namibia has data available for DHS II (1992), DHS IV (2000) and DHS V (2006). There is a total of 20,173 observations in DHS II, 22,332 in DHS IV and 29,725 in DHS V from 1410, 1687, and 2339 households respectively. We would be looking at the effect of wealth, parents' educational characteristics, household head characteristics, family

\section{http://repository.uwc.ac.za}


Table 2 presents the results from the analyses of DHS data from Namibia in 1992 (DHS II), 2000 (DHS IV) and 2006 (DHS V) respectively. Synonymous with the saying "two heads are better than one", children in the household with a single parent have a lower probability of attaining at least primary education compared with children in the household with both parents. Children in a household with both parents have a higher chance of having at least primary education, and these probabilities increase over time. The implication is that the contribution of having both parents on educational attainment in Namibia cannot be overemphasized. The odds increase from about 1 in 1992 to 21 in 2006.

The position of a child in the family plays a very important role in who goes to school first and who does the domestic work. The results here showed that the lower "ranking" a child has in a family, the less chance he/she has to attain at least primary education. That implied the first child has more priority than others. Also, these significant results indicate an increase in its importance over time.

Interestingly, the gender of the household head does not play a significant role in educational attainment in Namibia. The age of household head and number of household members were both positive and significantly associated with educational attainment. These results must be carefully interpreted, as the definition of household plays a very important role here.

The number of wives in the household, which is correlated with number of household members, has a significant influence on educational attainment of the children. The influence of number of wives was not significant in 1992 and 2000, but was negatively significant in 2006. Therefore, the more the number of wives in a household increases, the less are the chances of their children attaining at least primary education.

Gender has been a very important variable, especially in Africa. Interestingly, this may be a prejudice in the case of Namibia; in 1992 the effect gender was significant and the chance of a male child was about 1,2 times that of female child of attaining at least primary education. By 2006, the chances of a male child have dropped and gender is no longer a significant variable. Looking at the type of residence, the likelihood of people living in rural areas attaining at least primary education is less than that of those living in urban areas.

\section{Conclusion}

Against the descriptive background of educational attainment in African countries, an indepth analysis if Namibia revealed its status with respect to poverty factors. Results from the analysis of correlated DHS survey data from Namibia indicated that the following indicator variables had a significant effect on educational attainment: rank of the child, age of household head, number of household members, father alive, gender, parent's education and wealth index. The wealth index quintile also has a positively significant influence on educational attainment. As one would expect, the richer the household is, the more they are likely to have at least primary education.

\section{http://repository.uwc.ac.za}


Table 2: Results from GEE modelling of educational attainment for Namibia: DHS II-DHS V (No education against at least primary education)

\begin{tabular}{|c|c|c|c|c|c|c|c|c|c|}
\hline \multirow[b]{2}{*}{ Parameter } & \multicolumn{2}{|c|}{ DHS II (1992) } & \multicolumn{3}{|c|}{ DHS IV (2000) } & \multicolumn{4}{|c|}{ DHS V (2006/2007) } \\
\hline & $\begin{array}{l}\text { Esti- } \\
\text { mate }\end{array}$ & $\begin{array}{c}\text { Std. } \\
\text { Error }\end{array}$ & p-ralue & $\begin{array}{l}\text { Esti- } \\
\text { mate }\end{array}$ & $\begin{array}{c}\text { Std. } \\
\text { Error }\end{array}$ & p-ralue & $\begin{array}{l}\text { Esti- } \\
\text { mate }\end{array}$ & $\begin{array}{c}\text { Std. } \\
\text { Error }\end{array}$ & p-ralue \\
\hline $\begin{array}{l}\text { Intercept } \\
\text { Single Parent (YES) }\end{array}$ & $\begin{array}{l}-0,0372 \\
-0,2100\end{array}$ & $\begin{array}{l}0,8473 \\
0,1641\end{array}$ & $\begin{array}{l}0,9649 \\
0,2006\end{array}$ & $\begin{array}{l}-1,3180 \\
-0,2040\end{array}$ & $\begin{array}{l}1,3190 \\
0,2217\end{array}$ & $\begin{array}{l}0,3178 \\
0,3583\end{array}$ & $\begin{array}{r}3,2441 \\
-0,1985\end{array}$ & $\begin{array}{l}2,1362 \\
0,2415\end{array}$ & $\begin{array}{l}0,1289 \\
0,4110\end{array}$ \\
\hline Rank of Child & $-0,2884$ & 0,0233 & $<, 0001$ & $-0,4830$ & 0,0449 & $<, 0001$ & $-0,6620$ & 0,0314 & $<, 0001$ \\
\hline Sex of head (MLALE) & 0,4273 & 0,2390 & 0,0738 & 0,4019 & 0,5089 & 0,4297 & $-1,8242$ & 1,0446 & 0,0808 \\
\hline Age of head & 0,0450 & 0,0037 & $<, 0001$ & 0,0635 & 0,0044 & $<, 0001$ & 0,0799 & 0,0047 & $<, 0001$ \\
\hline Number of household member & 0,1662 & 0,0203 & $<, 0001$ & 0,3284 & 0,0381 & $<, 0001$ & 0,4551 & 0,0241 & $<, 0001$ \\
\hline Number of wives & $-0,1732$ & 0,1216 & 0,1544 & $-0,1310$ & 0,4824 & 0,7857 & $-2,2922$ & 1,0419 & 0,0278 \\
\hline Mother alive (NO) & $-0,8234$ & 0,5325 & 0,1221 & $-1,0830$ & 0,4686 & 0,0209 & $-2,1744$ & 0,4260 & $<, 0001$ \\
\hline Father alive (NO) & $-1,3950$ & 0,4519 & 0,0020 & $-1,0720$ & 0,3997 & 0,0073 & $-0,9289$ & 0,4285 & 0,0302 \\
\hline Gender (MALE) & 0,1502 & 0,0623 & 0,0158 & 0,0749 & 0,0769 & 0,3298 & 0,0815 & 0,0552 & 0,1399 \\
\hline Type of residence (RURAL) & $-0,2329$ & 0,1311 & 0,0757 & $-0,4150$ & 0,1153 & 0,0003 & $-0,1916$ & 0,0822 & 0,0197 \\
\hline Wealth Index & 0,0076 & 0,0406 & 0,0415 & 0,0536 & 0,0393 & 0,0032 & 0,0694 & 0,0332 & 0,0367 \\
\hline $\begin{array}{l}\text { Fathers highest education } \\
\text { Mothers highest education }\end{array}$ & $\begin{array}{l}0,0465 \\
0,2476\end{array}$ & $\begin{array}{l}0,0654 \\
0,0647\end{array}$ & $\begin{array}{l}0,4771 \\
0,0001\end{array}$ & $\begin{array}{l}0,2824 \\
0,2244\end{array}$ & $\begin{array}{l}0,0448 \\
0,0553\end{array}$ & $\begin{array}{r}<, 0001 \\
<, 0001\end{array}$ & $\begin{array}{l}0,2293 \\
0,2703\end{array}$ & $\begin{array}{l}0,0574 \\
0,0604\end{array}$ & $\begin{array}{l}<, 0001 \\
<, 0001 \\
\end{array}$ \\
\hline
\end{tabular}

In conclusion, the case study of Namibia from 1992-2006 indicated that socio-economic indicators play a significant role in educational attainment. Families with higher socioeconomic resources tend to send their children to school more often than poorer families, and the parent's level of education may also play an important role in their perception of the value for schooling. In developing countries, parents are bestowed with the sole responsibility of sending their children to school; therefore they weigh the immediate cost carefully (Jannie \& Jeroen, 2009). Families with both parents gainfully employed may have higher bargaining power than a family with one parent providing for the entire family. Further, family size plays a very important role and impacts on the wealth distribution in the household. The position of a child in the family may affect the continuation of schooling for other members of the family.

Finally, the idea of this study was to provide an empirical analysis of geographical heterogeneity of African countries in educational attainment and poverty with special reference to Namibia as case study. Further studies will include investigating statistical issues as related to parameter estimation techniques and missing data. 


\section{References}

Alabi, R.A. 2008. Income distribution and accessibility to primary and secondary schools in Nigeria. Tech. Rept. Institute for World Economics and International Management, University of Bremen.

Aluede, R.O. 2006. 'Regional demands and contemporary educational disparities in Nigeria', Journal of Social Sciences, 13(3): 183-189.

Barro, R. \& Lee J. 2010. 'A new data set of educational attainment in the world, 19502010'. Tech. rept. National Bureau of Economic Research Working Paper Series. Bledsoe, C., John, C., Jennifer, J. K. \& John H. 1999. Critical perspectives on schooling and fertility in the developing world. Washington, DC: National Academy Press. Breslow, N. \& Clayton, D.G. 1993. 'Approximate inference in generalized linear mixed models', Journal of American Statistical Association, 88: 9-25.

Chatfield, C. \& Collins, A.J. 1980. Introduction to multivariate data analysis. London: Chapman and Hall.

Chiswick, B. 1971. 'Earnings inequality and economic development', Quarterly Journal of Economics, 85:21-39

Collier, P. 2007. 'Economic causes of civil conflict and their implications for policy'. In Crocker, A., Hampson, F.O., \& Aal, P. (eds.). Leashing the dogs of war: Conflict management in a divided world. Washington, DC: USIP Press.

Deng, L.B. 2003. 'Education in southern Sudan: War, status and challenges of achieving education for all goals'. Tech. Rept. EFA Global Monitoring Report. [online] URL:http://www.unesco.org/en/efareport/reports/20034-gender Diggle, P.J., Liang, K.Y. \& Zeger, S.L. 1994. Analysis of longitudinal data. Oxford: Oxford Science Publications.

Diggle, P., Heagerty, P., Liang, K.Y. \& Zeger, S.L. 2002. Analysis of longitudinal data. New York: Oxford University Press.

Education Policy and Data Centre. 2012. Namibia core USAID education profile. [online] URL:http://www.epdc.org/sites/default/files/documents/Namibia_coreusaid.pdf EFA. 2002. Education for all: Is the world of track? Global Monitoring Report'. [online] URL:http://www.unesdoc.unesco.org/images/0012/001297/129777e.pdf

Fahrmeir, L. \& Tutz, G.T. 2001. Multivariate statistical modelling based on generalized linear models. New York: Springer-Verlag,

Gardner, R. 1998. 'Education'. Tech. rept. DHS Comparative Studies No. 29.

Gibson, J. 2002. 'Why does the Engel method work? Food demand, economies of size and household survey methods', Oxford Bulletin of Economics and Statistics, 64(4): 341-360. Hedeker, D. 2005. Generalized linear mixed models. In Everitt. B. \& Howell, D. (eds.). Encyclopaedia of statistics in behavioural science. London: John Wiley \& Sons Inc. Jannie, H. \& Jeroen, S. 2009. 'Effects of household and district-level factors on primary school enrolment in 30 developing countries', World Development, 37(1):179-193. Liang, K.Y. \& Zeger, S.L. 1986. 'Longitudinal data analysis using generalized linear models', Biometrika, 73: 13-22.

Levine, S. \& Roberts, B. .2008. Dynamics of income inequality and poverty in postindependence Namibia. Presentation, UNU-WIDER Conference, Finland.

McCullagh, P. \& Nelder, J.A. 1989. Generalized linear models. London: Chapman and Hall.

MeasureDHS. 2010. Demographic and health surveys. [online]

URL:www.measuredhs.com 
Pendergast, J.F., Gange, S.J., Newton, M.A., Lindstrom, M.J., Palta, M. \& Fisher, M.R. 1996. 'A survey of methods for analyzing clustered binary response data', International Statistical Review, 64: 89-118.

Psacharopoulos, G. \& Arriagada, A. 1986. 'The educational composition of the labour force', International Labour Review, 125: 561-574 .

Pullum, T.W. 2008. 'An assessment of the quality of data on health and nutrition in the DHS surveys, 1993-2003', DHS Methodological Reports No. 6.

Ravallion, M. 1994. Poverty comparisons: fundamentals of pure and applied economics. Switzerland: Harwood Academic Publishers.

Rutstein, S.O. \& Kiersten J. 2004. 'The DHS wealth index', DHS Comparative Reports No. 6.

The Ombudsman. 2010. Namibia (NHRI) submission to the universal periodic review mechanism. [online]

URL:http://lib.ohchr.org/HRBodies/UPR/Documents/Session10/NA/The\%2oOmbuds man_TheOfficeoftheOmbudsman-eng.pdf

Thomas, V., Wang, Y. \& Fan, X. 2001. Measuring education inequality: Gini coefficients of education, Tech. Rept. World Bank Policy Research Working Paper No. 2525.

Townsend, P. 1979. Poverty in the United Kingdom: A survey of household resources and standards of living. Harmondsworth: Penguin Books

United Nations. 1948. 'The universal declaration of human rights'. [online] URL: www.un.org

Van der Berg, S. \& Moses, E. 2011. The remarkable improvement in functional literacy and numeracy in Namibia: A comparison between SACMEQ II and III. [online] URL:http://www.sacmeq.org/downloads/OtherPolbriefs/SACMEQ\%20NAMIBIA\%20Po licy\%2oBrief\%20-\%20Final\%20Oct2011.pdf

Verbeke, G. \& Molenberghs, G. 2000. Linear mixed models for longitudinal data. New York: Springer-Verlag.

Vernon, G. \& Paul, L. 2011. 'An analysis of detailed parental occupational differences and their effects on children's school attainment in Britain'. Tech. Rept. ISA Research Committee 28.

Zeger, S.L., Liang K.Y. \& Albert P.S. 1988. 'Models for longitudinal data: A generalized estimating equation approach', Biometrics, 44: 1049-6o. 
Appendix 1: Map showing the total number of observations used in this study

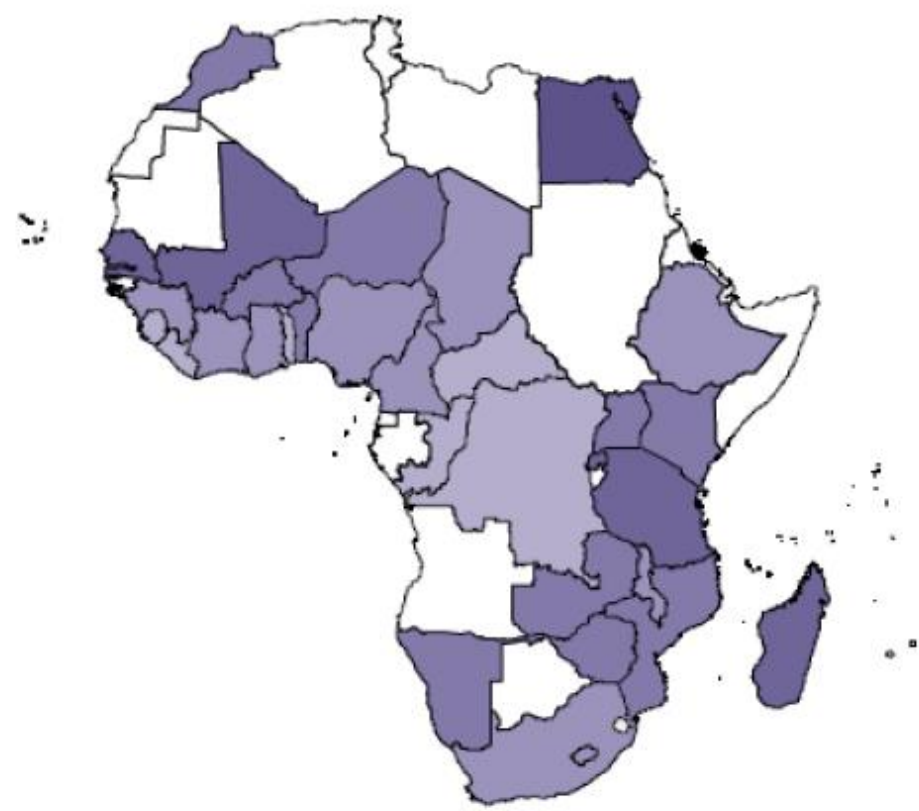

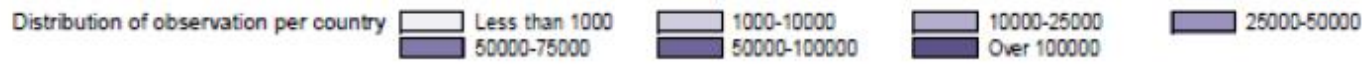

\section{Appendix 2: General variable definitions and description}

\begin{tabular}{ll}
\hline Variable & Description \\
\hline Relationship to head & Son/Daughter/ Adopted/Foster/Stepchild Or Other Relation \\
Single parent & Yes, Both Parent Are Dead Or No, At Least One Is Alive \\
Mother's education level & No Education, Primary Or Secondary \\
Father's education level & No Education, Primary Or Secondary \\
Father's age & Years \\
Mother's age & Years \\
Wealth index & Poorest, Poor, Middle, Rich, Or Richest \\
Total number of family members & Count \\
Type of residence & Urban Or Rural \\
Gender & Male Or Female \\
Educational attainment & No Education, Primary, Or Secondary or Higher \\
Age & Years \\
Marital status & Yes Or No \\
Source of water & Clean Water (Piped Water,: Tube Well Or Borehole, Bottled Water \\
& ,Cart With Small Tank) Or Unclean Water (Dug Well, Water From \\
Type of toilet & Spring, Rainwater, Surface Water) \\
& Good Sanitation (Flush Or Pour Flush Toilet, Ventilated Latrine ) Or \\
Sex of head & Bad Sanitation (None Ventilated Latrine, Bucket, No Facility/Bush, \\
Age of head & Field) \\
Literacy gap & Male Or Female \\
Education Gini & Years \\
\hline & Gender Difference In The Proportion Of Male And Female With At \\
& Least Primary Education \\
& Calculated
\end{tabular}


Appendix 3: National educational system of the 36 African countries under study

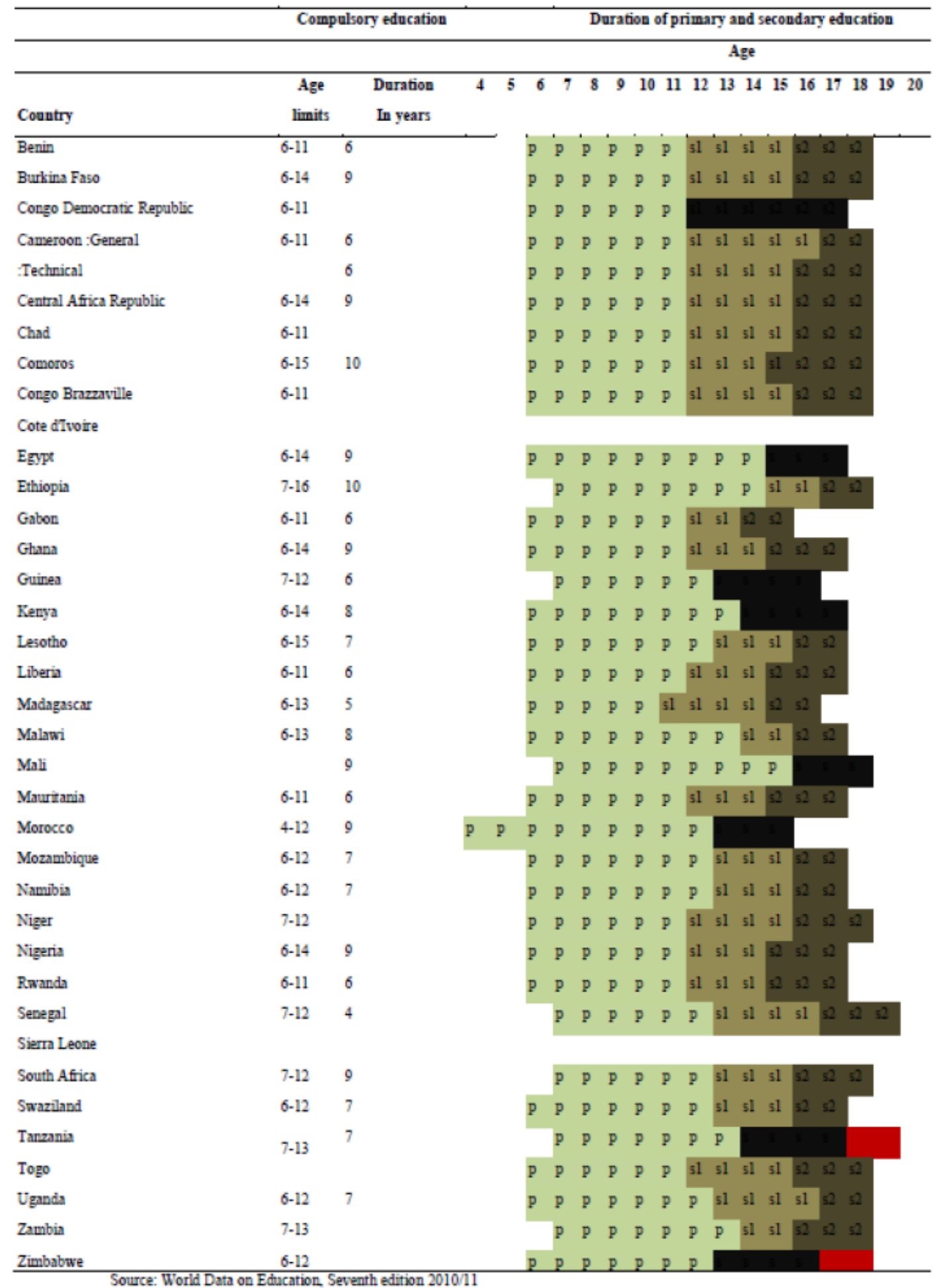

Primary school $\quad$ D $\quad$ Secondary School 1st stage Secondary School : Straight $\quad \square \quad$ Advanced level: Optionsl

51 Secondary School : 2nd stage 
Appendix 4: Distribution of literacy level: Proportion of total population with no education

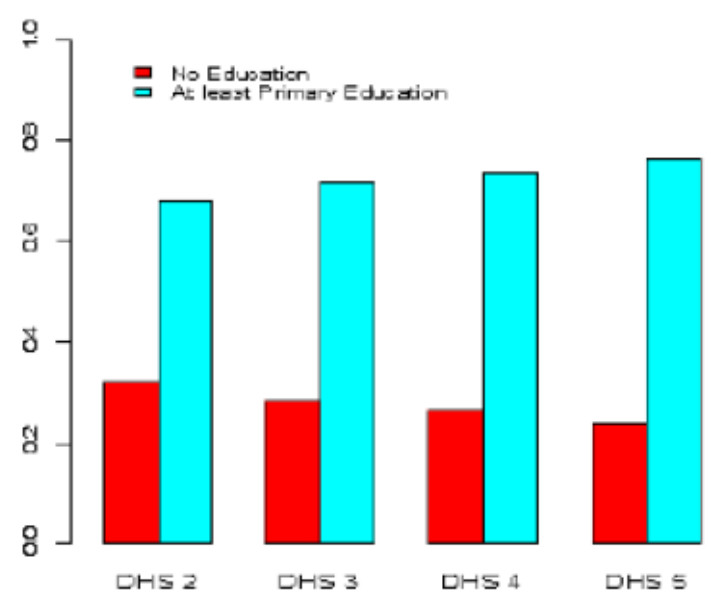

Appendix 5: Educational attainment indicated by highest level of education completed by country. Top is for DHS II (1988-1993) and bottom is for DHS III (1993-1998)
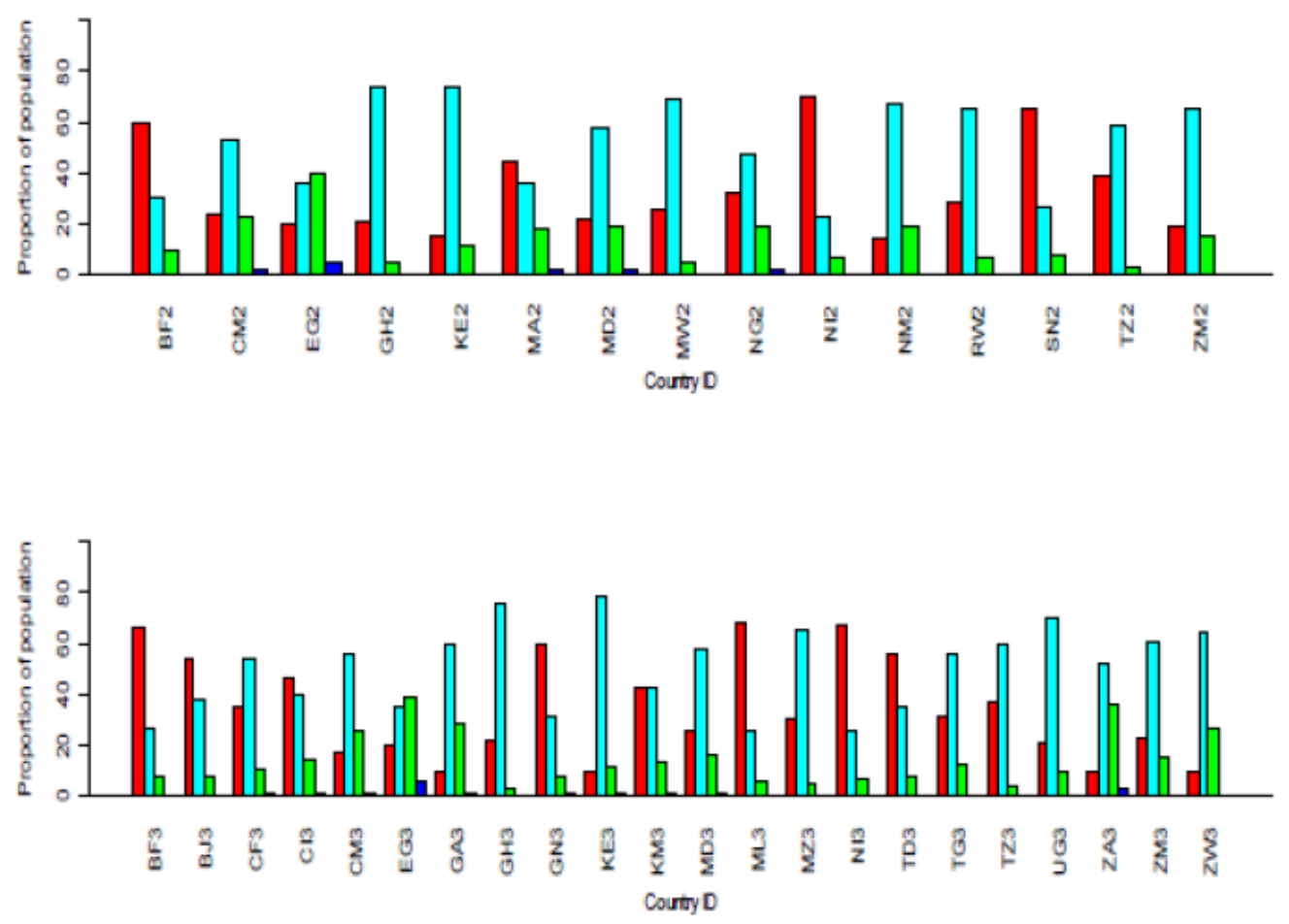

No education $\mid$ Primary education $\mid$ Secondary education $\mid$ Tertiary education $\mid$ 
Appendix 6: Mean wealth quintile, educational level and number of household by country

\begin{tabular}{|c|c|c|c|c|c|c|c|}
\hline Phase & Country & Code & $\begin{array}{l}\text { Mean wealth } \\
\text { index quintile }\end{array}$ & $\begin{array}{l}\text { Mean wealth } \\
\text { index score }\end{array}$ & $\begin{array}{c}\text { Mean } \\
\text { educational } \\
\text { level }\end{array}$ & $\begin{array}{c}\text { Mean } \\
\text { household } \\
\text { member }\end{array}$ & $\begin{array}{c}\text { Educational } \\
\text { Gini }\end{array}$ \\
\hline \multirow[t]{15}{*}{ DHS 2} & Burkina Faso & $\mathrm{BF} 2$ & 3,12175 & $-0,24$ & 0,36582 & 10,8656 & 0,73613 \\
\hline & Cameroon & $\mathrm{CM} 2$ & 3,11723 & $-0,05$ & 0,92111 & 9,8869 & 0,39706 \\
\hline & Egypt & $\mathrm{EG} 2$ & , & & 1,28592 & 8,1683 & 0,35319 \\
\hline & Ghana & $\mathrm{GH} 2$ & 3,04678 & 0,05 & 0,86135 & 6,5385 & 0,25837 \\
\hline & Kenya & $\mathrm{KE} 2$ & 3,01462 & $-0,06$ & 0,95485 & 7,5437 & 0,24306 \\
\hline & Moroceco & MA2 2 & 3,05350 & 0,01 & 0,77534 & 8,5372 & 0,54833 \\
\hline & Madagascar & $\mathrm{MD} 2$ & . & & 0,91253 & 7,7707 & 0,35670 \\
\hline & Malawi & $\mathrm{NW} / 2$ & 3,09100 & -0.05 & 0,70661 & 6,8269 & 0,35776 \\
\hline & Nigeria & NG2 & 3.09058 & -0.17 & 0.82725 & 9.2489 & 0.46639 \\
\hline & Niger & NI2 & & & 0.23965 & 10.6245 & 0.82477 \\
\hline & Namibia & $\mathrm{NM}_{2}$ & 3,01788 & $-0,06$ & 1,06442 & 10,4044 & 0,26745 \\
\hline & Rwanda & RW2 & 3,11171 & $-0,06$ & 0,76311 & 7,0453 & 0,34351 \\
\hline & Senegal & $\mathrm{SN} 2$ & , & . & 0.43244 & 13,9561 & 0,70897 \\
\hline & Tanzania & $\mathrm{TZ2}$ & , & , & 0,65459 & 8,7539 & 0,40539 \\
\hline & Zambia & $\mathrm{ZM} 2$ & ; & ; & 0,98610 & 8,7267 & 0,29361 \\
\hline \multirow[t]{21}{*}{ DHS 3} & Burkina Faso & $\mathrm{BF} 3$ & 3,07139 & $-0,15$ & 0,34334 & 10,6869 & 0,74842 \\
\hline & Benin & BJ3 & 3,10729 & 0,15 & 0,56366 & 9,8640 & 0,58445 \\
\hline & $\begin{array}{l}\text { Central Africa Republic } \\
\text { Cote dIvoire }\end{array}$ & $\begin{array}{l}\text { CF3 } \\
\text { CI1 }\end{array}$ & $\begin{array}{l}3,23216 \\
3,54405\end{array}$ & $\begin{array}{l}0,44 \\
0,10\end{array}$ & $\begin{array}{l}0,77470 \\
0,69386\end{array}$ & $\begin{array}{r}9,0966 \\
12,1208\end{array}$ & $\begin{array}{l}0,42961 \\
0,54671\end{array}$ \\
\hline & Cameroon & $\mathrm{CM} 2$ & 3,11010 & $-0,12$ & 1,03190 & 9,3842 & 0,33290 \\
\hline & Egypt & EG3 & 2,94182 & $-0,07$ & 1,33779 & 7,7790 & 0,33698 \\
\hline & Gabon & $\mathrm{GA}_{3}$ & 3,07308 & 0,42 & 1,28348 & 9,8022 & 0,25957 \\
\hline & Ghana & GH3 & 3,19512 & -0.22 & 0.80488 & 8.3171 & 0.24242 \\
\hline & Guinea & GN3 & 3.15584 & 0.15 & 0.48468 & 10.4004 & 0.67144 \\
\hline & Kenya & $\mathrm{KE} 3$ & 3,10328 & -0.02 & 1.05447 & 6.6231 & 0,19188 \\
\hline & Comoros & KM3 & 3,08261 & 0.07 & 0,72647 & 8.4148 & 0,51453 \\
\hline & Madagascar & $\mathrm{MD} 3$ & 3,10537 & $-0,06$ & 0,89115 & 7,2983 & 0,36447 \\
\hline & Mali & $\mathrm{ML} 3$ & 3,20444 & 0.30 & 0,37022 & 9,1818 & 0,73496 \\
\hline & Mozambique & $\mathrm{MZ3}$ & 3,19963 & 0,14 & 0,71592 & 7,3056 & 0,35799 \\
\hline & Niger & NI3 & 3,13731 & -0.03 & 0.33189 & 9,5221 & 0,75904 \\
\hline & Chad & ID3 & 3,10155 & $-0,12$ & 0,43864 & 8,9982 & 0,65899 \\
\hline & Togo & TG3 & 3,08636 & 0,10 & 0,86816 & 9,0500 & 0,37708 \\
\hline & Tanzania & TZ3 & 3,30029 & 0,03 & 0,66468 & 7,6669 & 0,40055 \\
\hline & Uganda & UG3 & 3,05425 & $-0,15$ & 0,84914 & 7,5472 & 0,29210 \\
\hline & South Africa & $\mathrm{ZA} 3$ & 2,93652 & -0.01 & 1.35499 & 6,4670 & 0,25848 \\
\hline & Zambia & $\mathrm{ZM} 3$ & 3,13254 & 0.35 & 0,96304 & 8,1218 & 0,33506 \\
\hline & Zimbabwe & ZW3 & 2,96414 & -0.08 & 1,19188 & 7,4533 & 0,24136 \\
\hline
\end{tabular}


Appendix 6: Mean wealth quintile, educational level and number of household by country continued

\begin{tabular}{|c|c|c|c|c|c|c|c|}
\hline Phase & Country & Code & $\begin{array}{l}\text { Mean wealth } \\
\text { index quintile }\end{array}$ & $\begin{array}{c}\text { Mean } \\
\text { wealth } \\
\text { index score }\end{array}$ & $\begin{array}{c}\text { Mean } \\
\text { educational } \\
\text { level }\end{array}$ & $\begin{array}{c}\text { Mean } \\
\text { household } \\
\text { member }\end{array}$ & $\begin{array}{c}\text { Educational } \\
\text { Gini }\end{array}$ \\
\hline \multirow[t]{24}{*}{ DHS 4} & Burkina Faso & BF4 & 3,12462 & 4910,75 & 0,41731 & 10,8159 & 0,71411 \\
\hline & Benin & $\mathrm{BJ} 4$ & 3,14041 & 0,13 & 0,71527 & 8,7254 & 0,50227 \\
\hline & Cameroon & CM4 & 3,12530 & 7387,10 & 1,11232 & 8,6323 & 0,30780 \\
\hline & Egypt & EG4 & 2,87794 & $-0,24$ & 1,42297 & 7,6476 & 0,32735 \\
\hline & Ethiopia & ET4 & 3,02144 & $-0,27$ & 0,44119 & 6,7701 & 0,67873 \\
\hline & Ghana & GH4 & 3,04563 & 7149,21 & 1,06012 & 6,6546 & 0,38869 \\
\hline & Guinea & GN4 & 3,14266 & 18923,19 & 0,60180 & 9,2299 & 0,60250 \\
\hline & Kenya & KE4 & 2.95880 & $-28078,46$ & 0,97666 & 6.6432 & 0.29285 \\
\hline & Lesotho & LS4 & 3,02846 & 4559,60 & 1,10788 & 6,6936 & 0,23988 \\
\hline & Morocco & MA4 & 3,00771 & 3689,54 & 1,09614 & 7,4760 & 0,39959 \\
\hline & Madagascar & MD4 & 3,05007 & $-48162,18$ & 0,95676 & 6,8012 & 0,31351 \\
\hline & Mali & MI4 & 3,13058 & 0,25 & 0,45506 & 8,7220 & 0,68183 \\
\hline & Mauritania & MR4 & 3,06843 & $-0,13$ & 0,69678 & 8,5831 & 0,53067 \\
\hline & Malawi & MW4 & 3,04588 & 0,02 & 0,92549 & 6,6184 & 0,22209 \\
\hline & Mozambique & $\mathrm{MZ4}$ & 3,20677 & 10990,04 & 0,79277 & 7,3017 & 0,35151 \\
\hline & Nigeria & NG4 & 3,08143 & 1272,51 & 1,05977 & 8,2141 & 0,42435 \\
\hline & Namibia & NM4 & 2,98757 & $-0,24$ & 1,10176 & 7,9422 & 0,33140 \\
\hline & Rwanda & RW4 & 3,20230 & $-0,03$ & 0,82328 & 6,2545 & 0,28013 \\
\hline & Senegal & $\mathrm{SN} 4$ & 3,09217 & 22937,63 & 0,63625 & 13,8189 & 0,57382 \\
\hline & Chad & TD4 & 3,06476 & $-20729,57$ & 0,52312 & 8,4016 & 0,62446 \\
\hline & Tanzania & TZ4 & 3,04472 & 4563,05 & 0,77570 & 7,9898 & 0,33311 \\
\hline & Uganda & UG4 & 3,14796 & $-0,12$ & 0,95949 & 7,6230 & 0,25296 \\
\hline & Zambia & ZM4 & 3,11952 & 0,35 & 0,94307 & 7,6539 & 0,35233 \\
\hline & Zimbabwe & ZW4 & 2,90483 & $-0,07$ & 1,24039 & 6,6598 & 0,25472 \\
\hline \multirow[t]{23}{*}{ DHS 5} & Benin & BJ5 & 3,07719 & 10333,80 & 0,84031 & 8,0481 & 0,45246 \\
\hline & CDR & CD5 & 3,17597 & 18278,25 & 1,09356 & 7,9839 & 0,34560 \\
\hline & Congo Brazzaville & CG5 & 3.08829 & $-438,97$ & 1,28265 & 8.3163 & 0.24898 \\
\hline & Cote dTvoire & CI5 & 3,14987 & 43407,63 & 0,86219 & 9,6788 & 0,50250 \\
\hline & Egypt & EG5 & 2,86335 & $-13085,83$ & 1,53136 & 6,8533 & 0,30393 \\
\hline & Ghana & GH5 & 2,99273 & 2948,10 & 1,12583 & 6,2431 & 0,37010 \\
\hline & Kenya & KE5 & 2,90630 & $-27497,42$ & 1,03587 & 6,4604 & 0,28328 \\
\hline & Liberia & LB5 & 3,17953 & 29069,61 & 0,67109 & 7,3763 & 0,58440 \\
\hline & Lesotho & LS5 & 2,96773 & 7519,04 & 1,24324 & 6,6768 & 0,23981 \\
\hline & Madagascar & MD5 & 3,07144 & $-3981,36$ & 1,05930 & 6,7985 & 0,28398 \\
\hline & Mali & MLS & 3,05933 & 10688,08 & 0,52081 & 8,6670 & 0,64554 \\
\hline & Mozambique & MZS & 3,20113 & $-2,88$ & 0,96205 & 6,2247 & 0,24107 \\
\hline & Nigeria & NGS & 3,78448 & 60061,80 & 0,94690 & 11,1638 & 0,46729 \\
\hline & Niger & NI5 & 3,05282 & $-13959,89$ & 0,38767 & 9,3778 & 0,70362 \\
\hline & Namibia & NMS & 2,98703 & $-4488,19$ & 1,26252 & 7,5346 & 0,29257 \\
\hline & Rwanda & RWS & 3,07261 & 5534,86 & 0,89843 & 6,1867 & 0,22121 \\
\hline & Sierra Leone & SL5 & 3,11553 & $-1008,91$ & 0,78013 & 8,0841 & 0,50537 \\
\hline & Senegal & SN5 & 3,07951 & 24785,92 & & 14,3565 & \\
\hline & Swaziland & SZ5 & 3,75000 & 13217,75 & 1,25000 & 6,5000 & \\
\hline & Tanzania & TZ5 & 3,06421 & 5429,17 & 0,87784 & 7,7666 & 0.25713 \\
\hline & Uganda & UG5 & 3,10423 & 7536,75 & 0,99053 & 7,5098 & 0.24440 \\
\hline & Zambia & ZM5 & 3,16159 & 17618,25 & 1,03861 & 7,0413 & 0,31351 \\
\hline & Zimbabwe & ZW5 & 3,02172 & $-2181,09$ & 1,26180 & 6,5082 & 0,25980 \\
\hline
\end{tabular}


Appendix 7: Wealth index comparisons by proportion (percentage) of the poorest $40 \%$ and the richest $20 \%$ of the population.
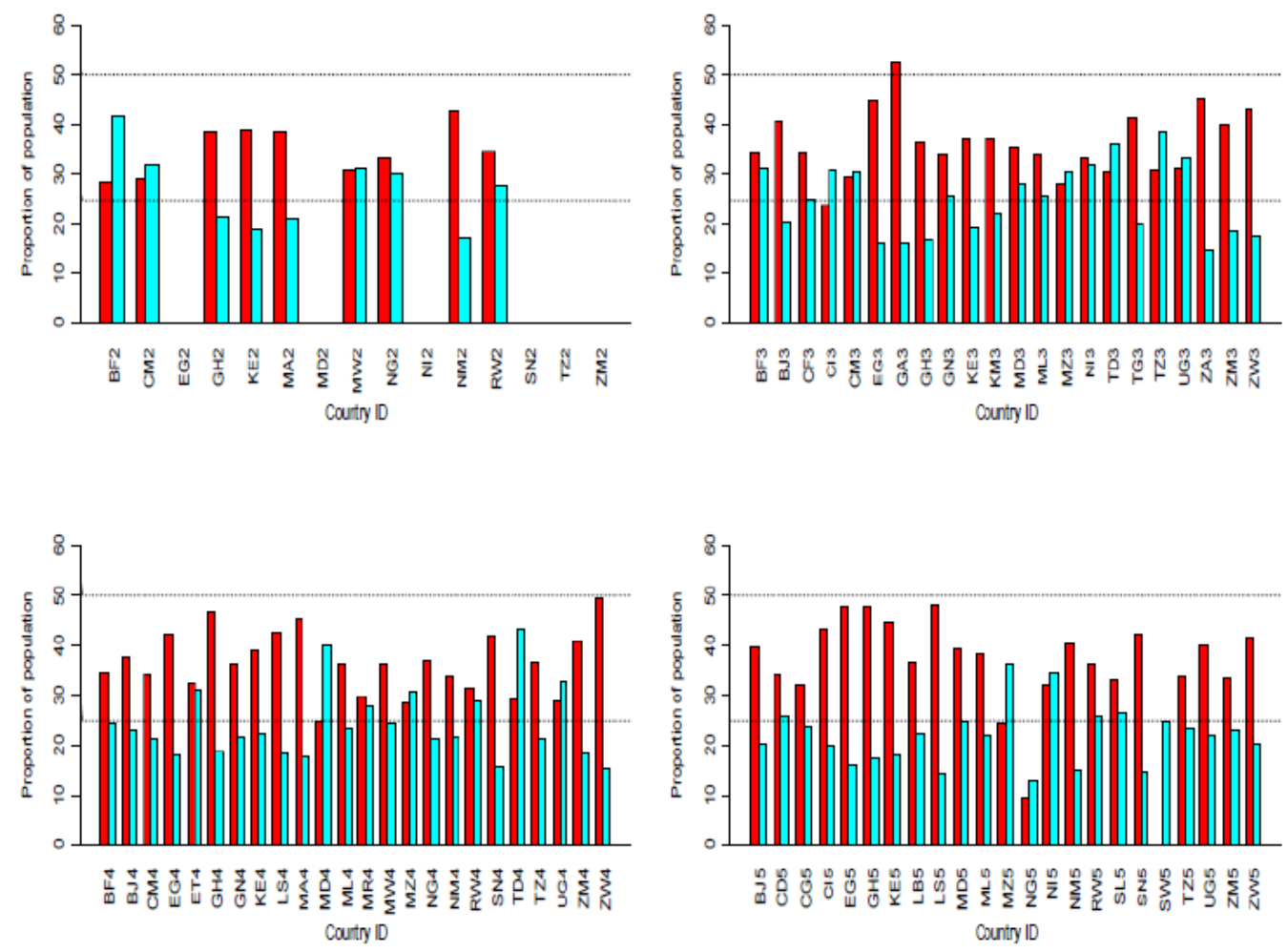

Poorest $40 \%$

Richest $20 \%$

Source: Authors' calculation from DHS (see appendix 1 for all the estimates and country code) 
Appendix 8: Gender difference in the proportion of males and females with at least primary education (literacy gap) for countries under study: Top left DHS II (1988-1993), Top right DHS III (1993-1998): Bottom left DHS IV (1998-2003): Bottom right DHS V (2003-2008)
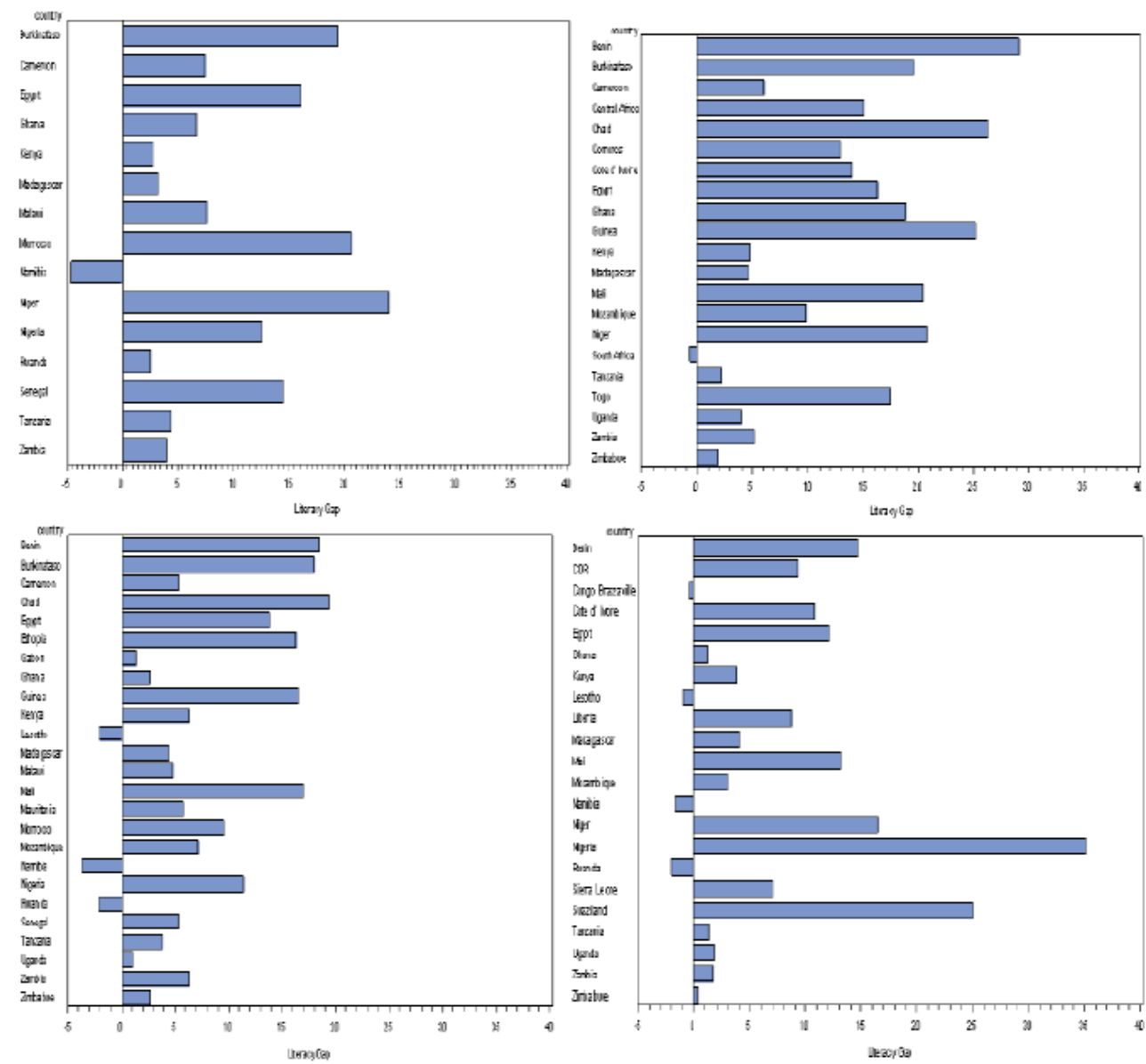